\title{
Star Enterprises Inc: Getting Control of Your Fixed Assets
}

Joseph M. Ragan (Email: jragan@sju.edu), Saint Joseph’s University

\begin{abstract}
Investment in fixed assets constitutes the largest part of the asset side of the balance sheet. This paper looks at the processes to create, purchase, manage, and evaluate the value and effectiveness of fixed assets using an SAP R/3 Resource Planning System. The case can be used to discuss a variety of issues associated with Asset accounting. This case is appropriate for an undergraduate course in accounting informational systems and/or intermediate accounting. The case does require access to an $S A P R / 3$ server, and some knowledge of how to navigate the $S A P R / 3$ system. The scenario uses the current version (ECC6.0) of SAP available to members of the SAP University Alliance.
\end{abstract}

$\mathscr{I}$ n July 2007, Todd Raymond, Senior Corporate Controller of Star Enterprises, Inc., called a meeting of his three best accountants and analysts to discuss the Company's ailing fixed asset system. He had mulled over enhancing this system for almost a year now, but had always gotten sidetracked with financial reporting, budgeting, and project analysis. He knew, however, that systems development was equally important, and decided not to wait any longer.

While many companies utilize fixed asset software to automate difficult depreciation and retirement calculations, Star Enterprises remained loyal to Microsoft Excel to handle the task. Raymond's philosophy was that the Company was already using the Excel package for other financial applications. Thus, as long as the proper system could be devised, sticking with Excel was the most cost effective decision. Besides, he strongly believed that his current system was failing largely due to a design flaw, and that the proper configuration of the data was the key to unleashing Excel's power to track the activities of Star Enterprises' fixed assets.

Raymond had confidence that his team could provide the "fix" on fixed assets that Star Enterprises desperately needed. He asked them to keep two main goals in mind when taking on this huge task. First, the Company needed a new, enhanced system. Since the current system was so poorly designed, and so clearly inadequate, he urged the team to scrap it and build a new one from the ground up. In prior years, they had attempted "band-aid" solutions, none of which destroyed the root of the problem. Second, he was certain that the current system was over-depreciating assets. This problem created more expense than should be allocated to operating divisions.

\section{THE CURRENT SYSTEM}

The current system was in existence since the Company began its operations on October 31, 2007. It was set up to track the Gross Fixed Asset activity and the Depreciation activity separately in two distinct fields in Excel. Raymond often referred to this system as a "rollforward" system. In essence, each month the system started with a beginning monthly balance and utilized the current month's activity to roll the balance forward to succeeding months.

For instance, the Gross Fixed Asset field started with the gross balance of assets for each specific asset category at a particular date. It then rolled the balance forward to the next month's beginning balance by adding

\footnotetext{
${ }^{1}$ Professors Ragan prepared this case as the basis for class demonstration and discussion of SAP R/3.
} 
additions of assets and removing retirements. Likewise, the Depreciation field started with the Accumulated Depreciation balance for each specific asset category at a particular month. Then the current month's depreciation expense was added, and the accumulated depreciation associated with any current retirements was removed to roll the Accumulated Depreciation balances forward. Table 1 below provides a simplified illustration of the rollforward process for the building asset category for several months. Note that Star Enterprises maintained a policy of depreciating additions in the month following the date the asset was placed in service.

Table 1: Illustration of Current "Rollforward" System: Buildings Category

Gross Fixed Assets Field: Buildings

$\begin{array}{ll}\text { Balance @ Oct. 31 } & \$ 360 \\ \text { Plus: Additions } & \$ 20 \\ \text { Less: Retirements } & \underline{\$ 0} \\ & \\ \text { Balance @ Nov. 30 } & \$ 380 \\ \text { Plus: Additions } & \$ 0 \\ \text { Less: Retirements } & \$ 00\end{array}$

Balance @ Dec.31

$\$ 380$
Accum. Depreciation Field: Buildings

\begin{tabular}{ll}
\hline Balance @ Oct. 31 & $\$ 0.00$ \\
Plus: Monthly Dep. & $\$ 2.00$ \\
Less: Retirements & $\underline{\$ 0.00}$ \\
& \\
Balance @ Nov. 30 & $\$ 2.00$ \\
Plus: Monthly Dep. & $\$ 2.11$ \\
Less: Retirements & $\$ \underline{\$ 0.00}$ \\
& \\
Balance @ Dec. 31 & $\$ 4.11$ \\
\hline
\end{tabular}

The one aspect of the above system which received the most focus from Raymond was the manner in which monthly depreciation expense was calculated. Raymond noticed that the system calculated depreciation expense on the total gross asset balance in any given month by lumping together the beginning gross balance with current additions and then calculating monthly depreciation expense on this total. He wanted his team to analyze this aspect of the current system when developing an enhanced model.

Secondly, Raymond focused a great deal of attention on the current system's lack of interface between the Purchasing Department and Accounts Payable. We need to know more about the status of the asset from delivery to payment, noted Raymond.

\section{THE STRATEGY MEETING}

When the three accountants met that evening they decided to keep it brief because the intense meeting with Raymond had drained their energy levels, and because the team so conveniently remembered that an episode of The Apprentice was airing at 9PM.

Thus, they decided to focus on the end product, with the details to be filled in along the way. They discussed how they would actually present the soon-to-be-developed new system to Raymond to ensure they didn't confuse his "senior level" mind. They agreed that it would be best to develop a prototype with several months of actual asset activity so they could thoroughly explain each aspect of their invention without allowing a mountain of data to cloud the picture during the meeting.

The team heard many things about the innovation features of Enterprise Resource Planning Software (ERP) integrates business functional areas. Before ERP, each functional area operated independently, using its own information systems and ways of recording transactions. ERP software also makes management reporting and decision making faster and more uniform throughout an organization. A key advantage to integrating SAP's fixed asset system is that each asset is separately recorded and separately depreciated. The fixed asset module also contains simulation and "what if" capability with regard to dollar values recorded for a fixed asset. In addition, ERP promotes thinking about corporate goals, as opposed to thinking only about the goals of a single department or functional area. They decided that SAP, the leading "solutions" firm, was their answer.

Besides the presentation they would give to Raymond, they also decided that it would be prudent to develop a formal report to Star Enterprises' Executive Management Committee to provide documentation of the 
project. Among other things, they would address the goals of their study, the current systems and its weaknesses, the specifics of the enhanced system, and how the enhancements would solve the problems faced by Star Enterprises.

With such direction now set, they decided to meet at $8 \mathrm{AM}$ the next morning to begin the task. Two weeks was not much time, so they figured they had better get an early jump on this challenge.

\section{EXERCISES}

I. Identify the problems caused by Star Enterprises' current system and then explain how an ERP system can help correct those problems? What are the costs? What are the benefits?

II. As a member of the Implementation Team, you have to set up (within SAP) the organizational structures and master data for the Asset Management Module. As you progress through this scenario you will experience the integration of several major modules within SAP R/3:
a) Create an asset record
b) Record acquisition of new asset
c) Display asset value, depreciation and book values
d) Display balance in asset class and individual assets comprising the class
e) Development a series of reports for presentations

III. Using the Asset Explorer, download the carrying value of your asset to Microsoft Excel and prepare a capital budgeting analysis of the profitability and value of this asset. The asset generates $\$ 60,000$ per year in incremental cash flows. The corporate board would like the capital budgeting analysis to indentify different hurdle rates ranging between $8 \%-16 \%$. The board would also like to know the internal rate of return, and remember our tax rate is $38 \%$.

IV. The fixed asset management module within SAP R/3 has interfaces to many other modules. What are those other modules? Describe the point of interface at which the point this occurs. What is the link to the Controlling module? What is the link to the Materials Management module?

V. The controller advises you that Star Enterprises has a buyer for the fixed assets you have just purchased. The buyer has offered $\$ 80,000$. Should the company pursue this offer? If yes, please record the sale and report the financial effects to the controller. How would this be reported on the cash flow report.

This application uses SAP ECC6.0 version

\section{FIXED ASSETS}

All business processes are accompanied by a supporting accounting structure that captures the financial impact of the process for either internal or external reporting purposes. The processes of buying, selling and producing assets are supported by a certain accounting structure as well. Within that structure, assets are organized into classes. Classes are types of assets such as real estate, buildings or equipment. Furthermore, a master record must exist and will contain the vital information about the asset such as its useful life, the method that is used to depreciate it and its salvage value. The asset can even be assigned to a vendor so that its origin is known.

\section{SECTIONS}

1. Asset Classes/Master Records

2. Asset Acquisition with Materials Management Integration 


\section{Section 1) Asset Classes/Master Records}

\section{Objectives:}

1. Display the different types of asset classes

2. Create an Asset Master File

3. Create Vendor Master Accounting Record

4. Create the Vendor Information Record and Master Purchasing Record

Objective 1) View the different types of asset classes maintained within IDES. Accounting $\rightarrow$ Financial

\section{Accounting $\rightarrow$ Fixed Assets $\rightarrow$ Asset $\rightarrow$ Create $\rightarrow$ Asset}

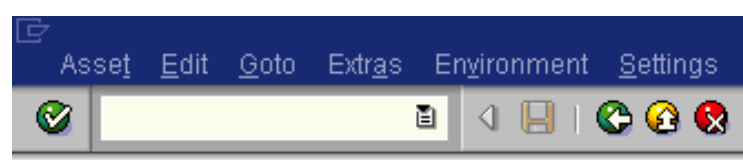

\section{Create Asset: Initial screen}

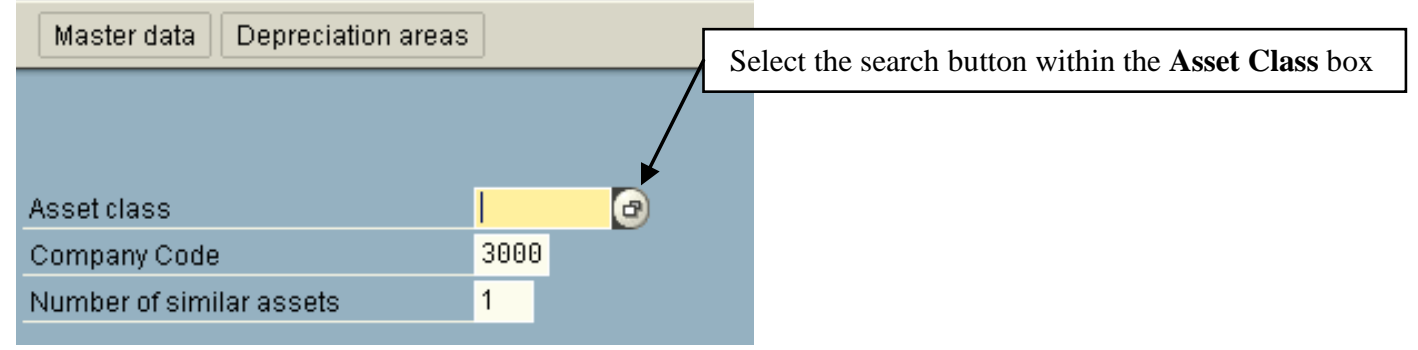

Enter the following information:

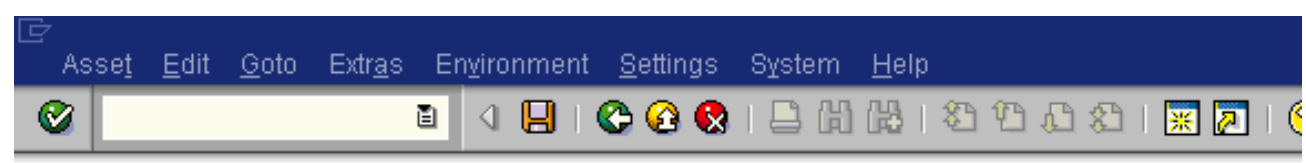

\section{Create Asset: Master data}

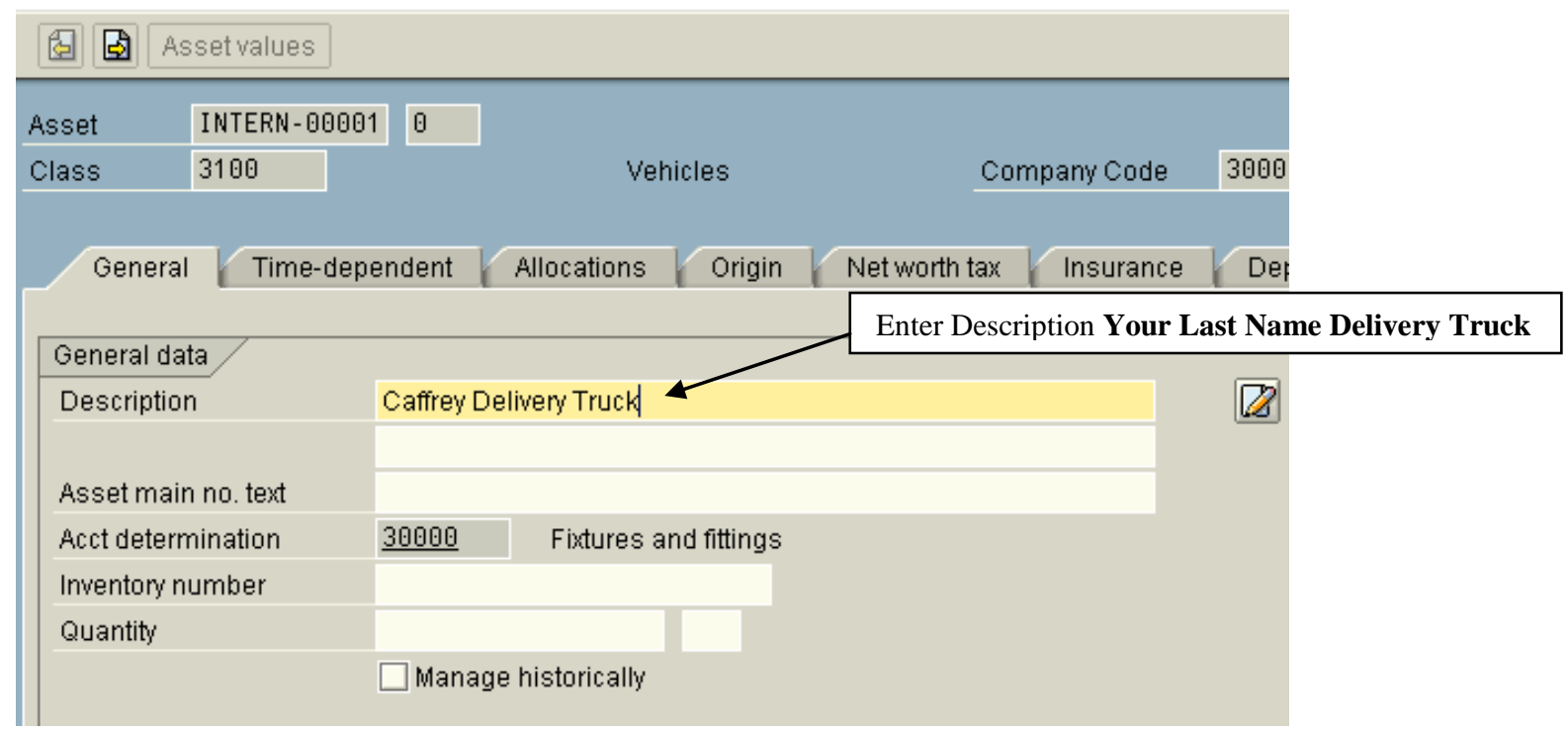


Click the Time-dependent tab and enter the following:

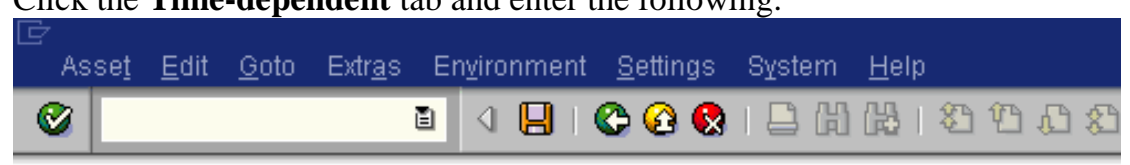

Create Asset: Master data

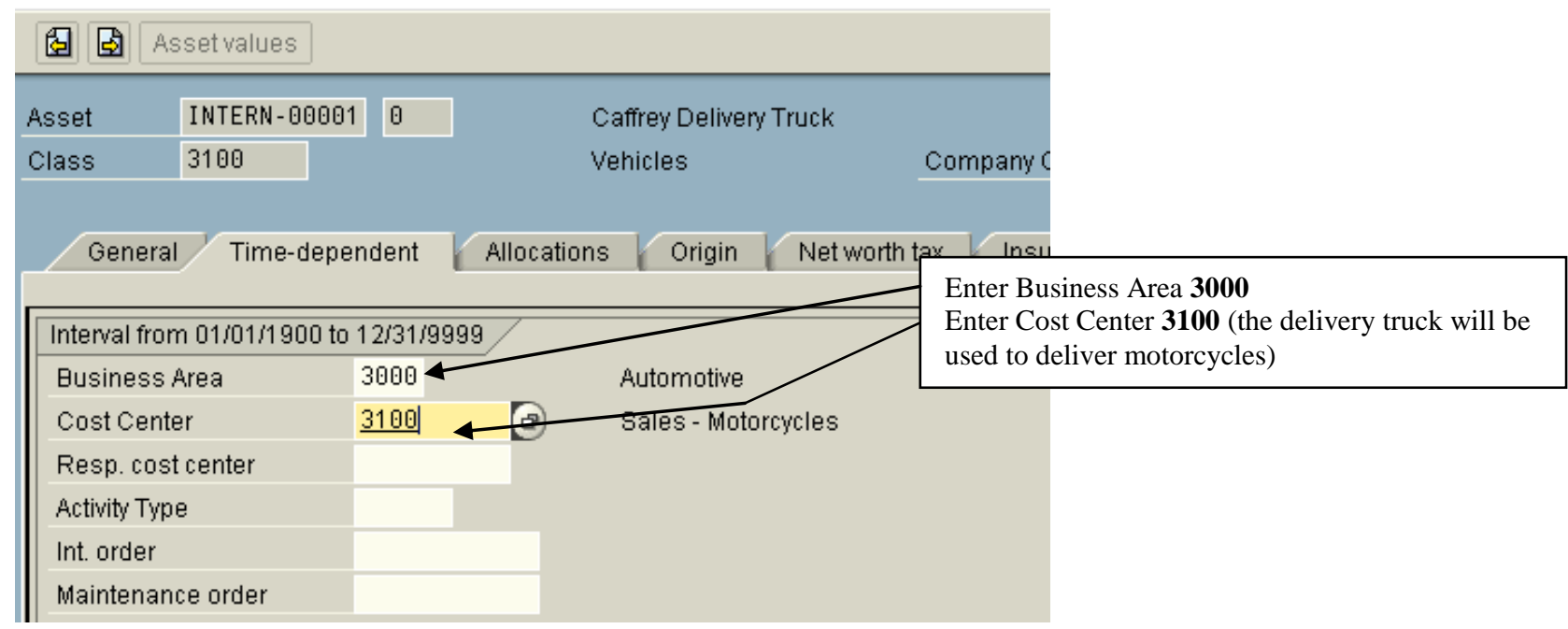

Hit the save ( $(\square)$ button.

Write down the asset number of your asset as seen on the bottom left hand corner of the screen:

Return to the SAP Easy Access Menu.

\section{Objective 3) Create Vendor Master Accounting Record. Accounting $\rightarrow$ Financial Accounting $\rightarrow$ Accounts} Payable $\rightarrow$ Master Records $\rightarrow$ Create

On the initial screen, enter the following information:

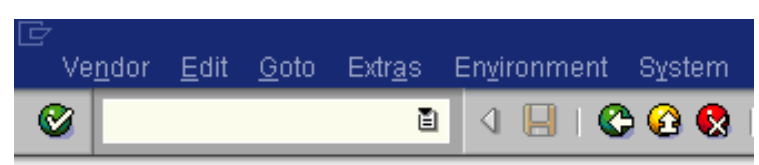

Create Vendor: Initial Screen

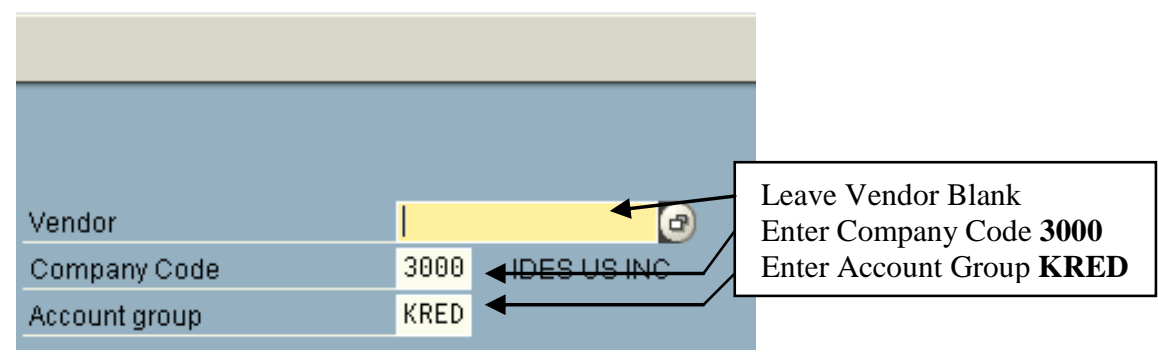

Hit the Enter $(9$ ) button.

On the next screen, enter the following: 


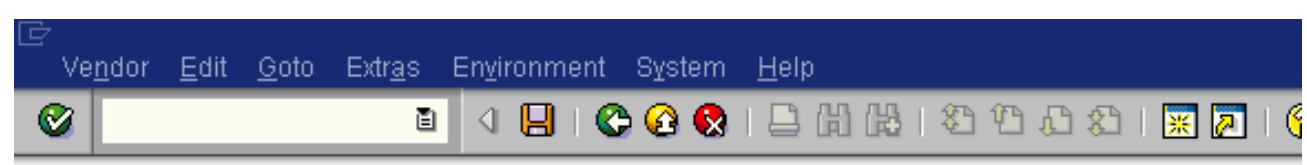

\section{Create Vendor: Address}

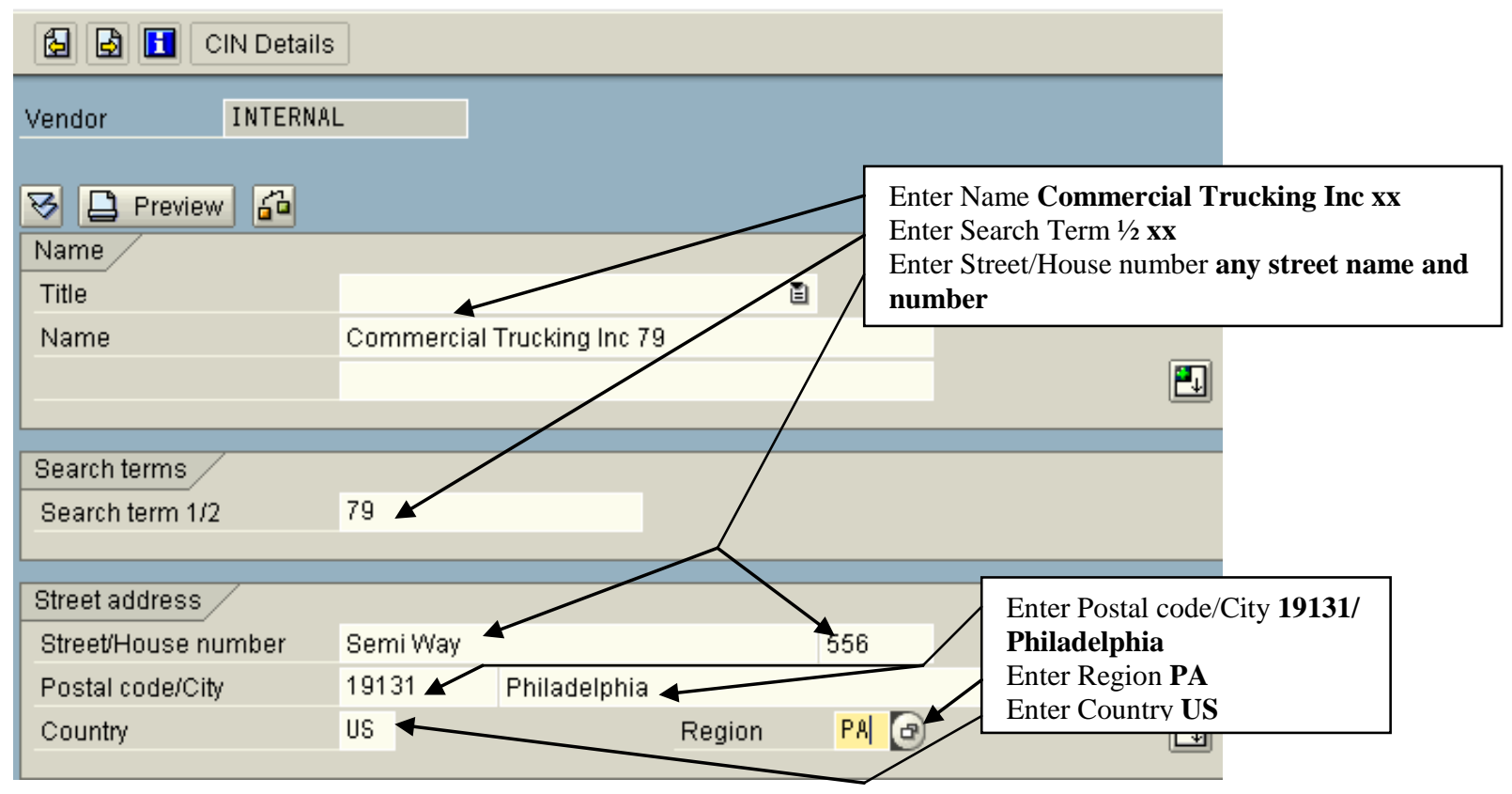

Hit the Enter $(\because)$ button repeatedly until you reach the following screen (Accounting Information Accounting):

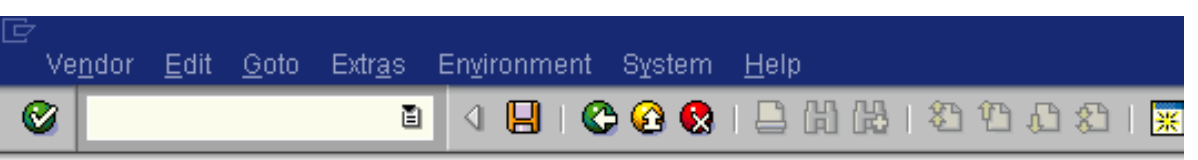

\section{Create Vendor: Accounting information Accounting}

\section{固 国 CIN Details}

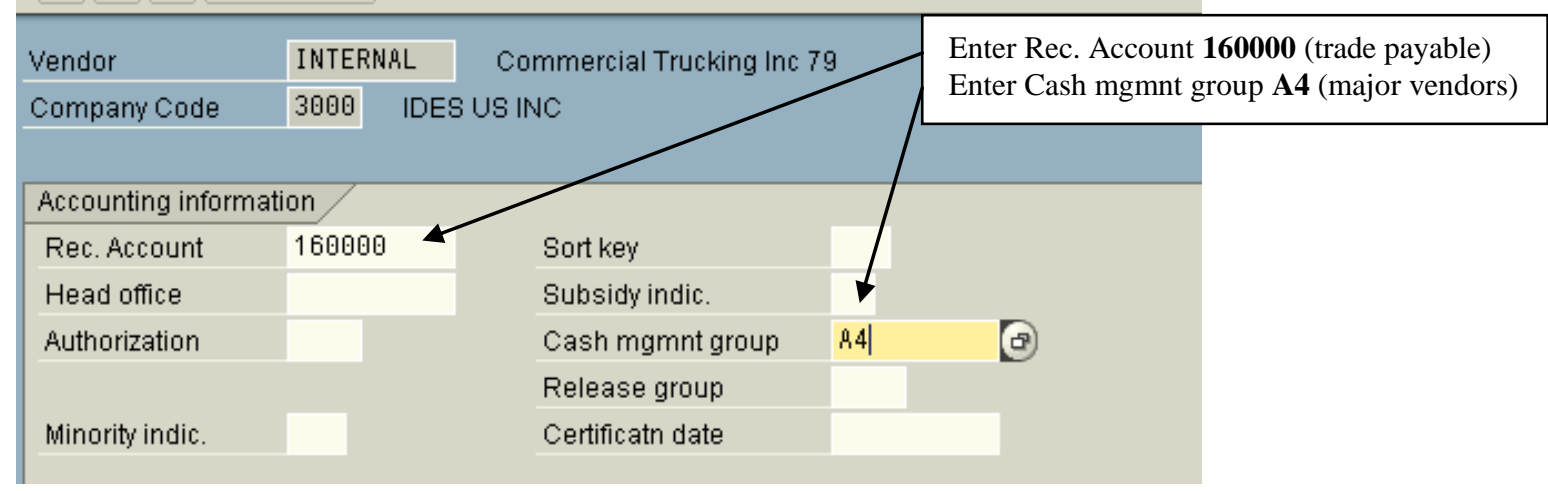

Hit the Enter $(\bullet)$ button.

On the next screen, enter the following: 


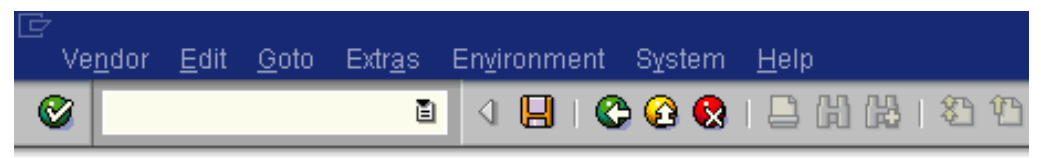

Create Vendor: Payment transactions Accounting

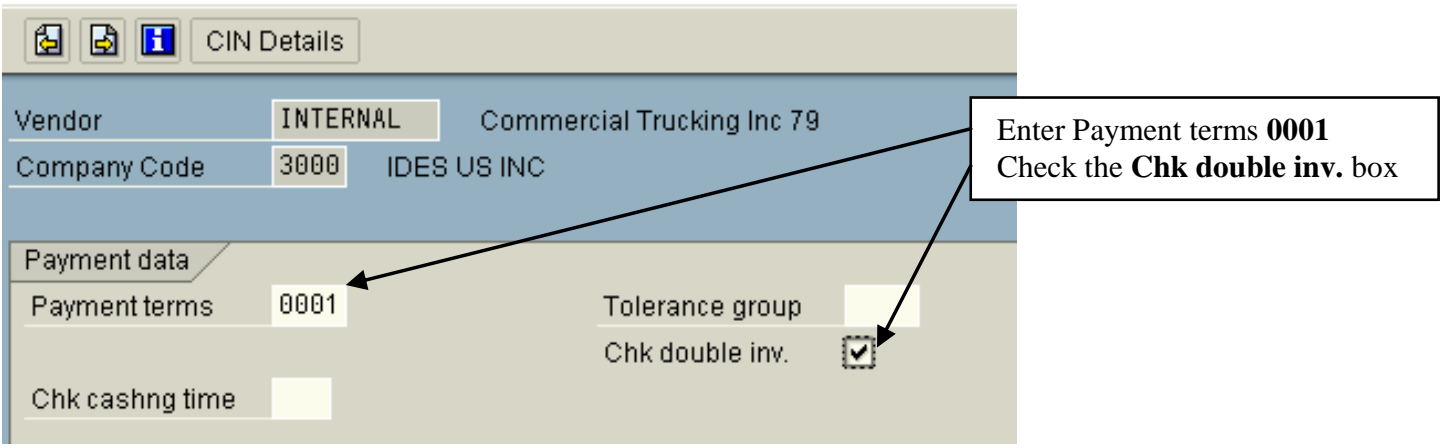

Hit the save ( $(9)$ button.

Record the Account Vendor Number:

Return to the SAP Easy Access Menu.

Objective 4) Create the Vendor Information record and Master Purchasing Record.

Create Vendor Master Purchasing Record:

Logistics $\rightarrow$ Materials Management $\rightarrow$ Purchasing $\rightarrow$ Master Data $\rightarrow$ Vendor $\rightarrow$ Purchasing $\rightarrow$ Create

On the initial screen, enter the following:

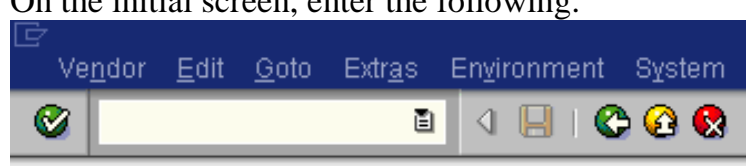

Create Vendor: Initial Screen

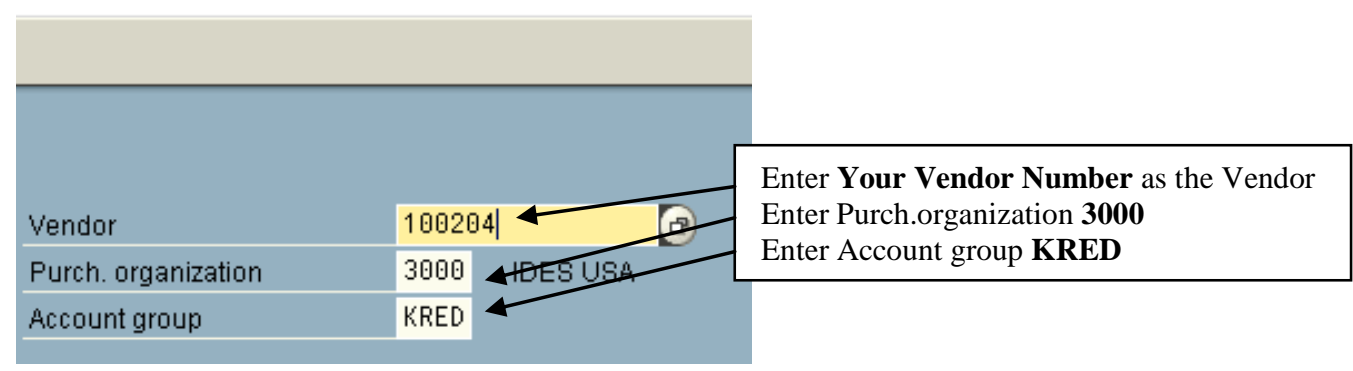

Hit the Enter (Q) button. 


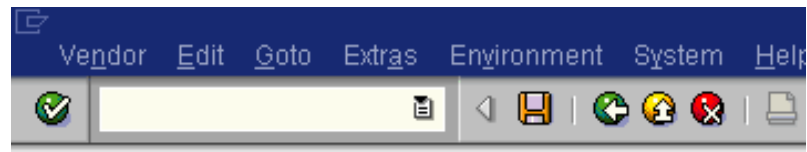

Create Vendor: Purchasing data

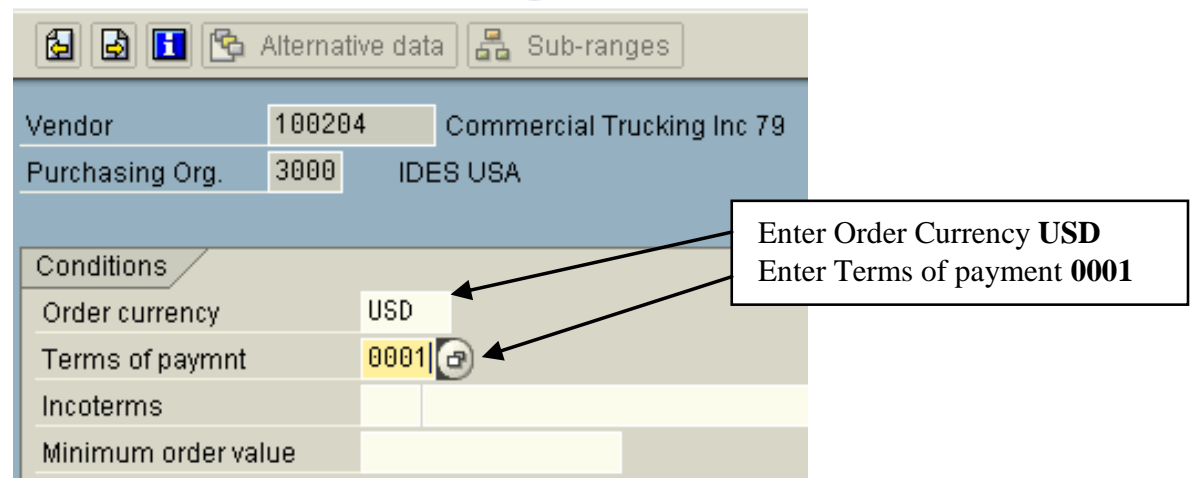

Hit the save ( $(\square)$ button.

Return to the SAP Easy Access Menu.

Create an Information Record

\section{Logistics $\rightarrow$ Materials Management $\rightarrow$ Purchasing $\rightarrow$ Master Data $\rightarrow$ Info Record $\rightarrow$ Create}

On the initial screen, enter the following:

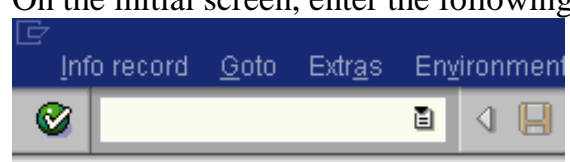

Create Info Record: Initial S,

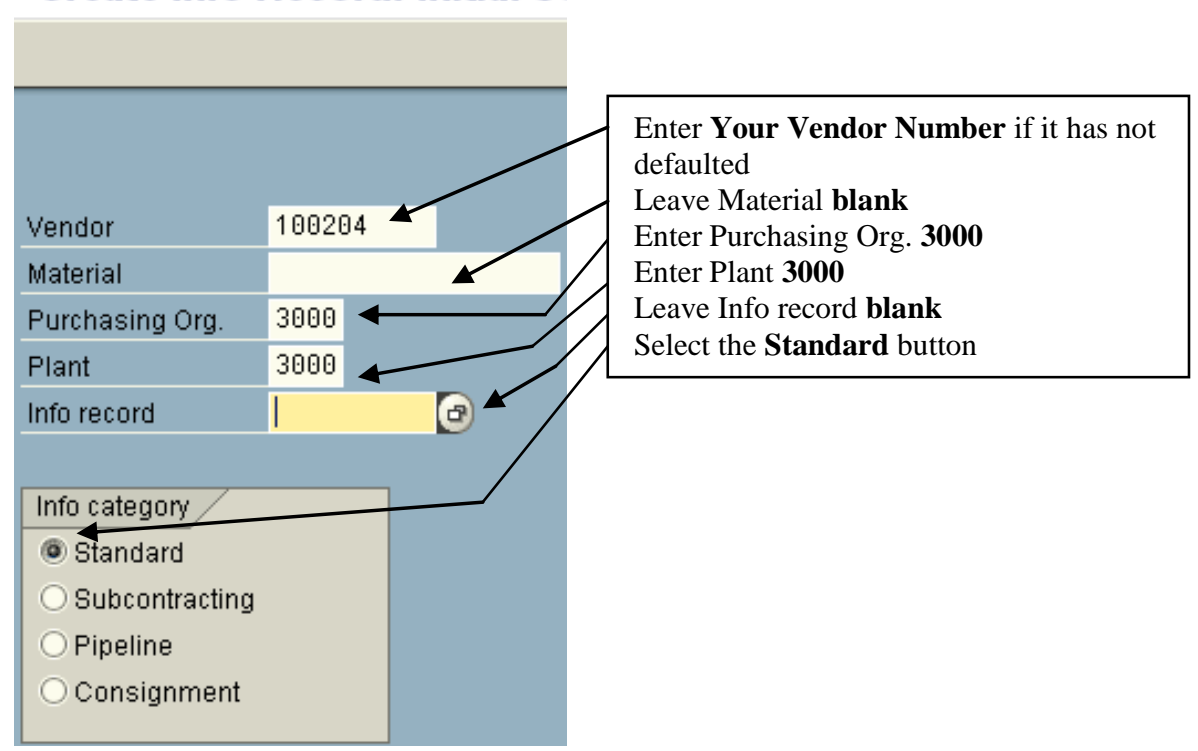

Hit the Enter (Q) button.

On the next screen, enter the following: 


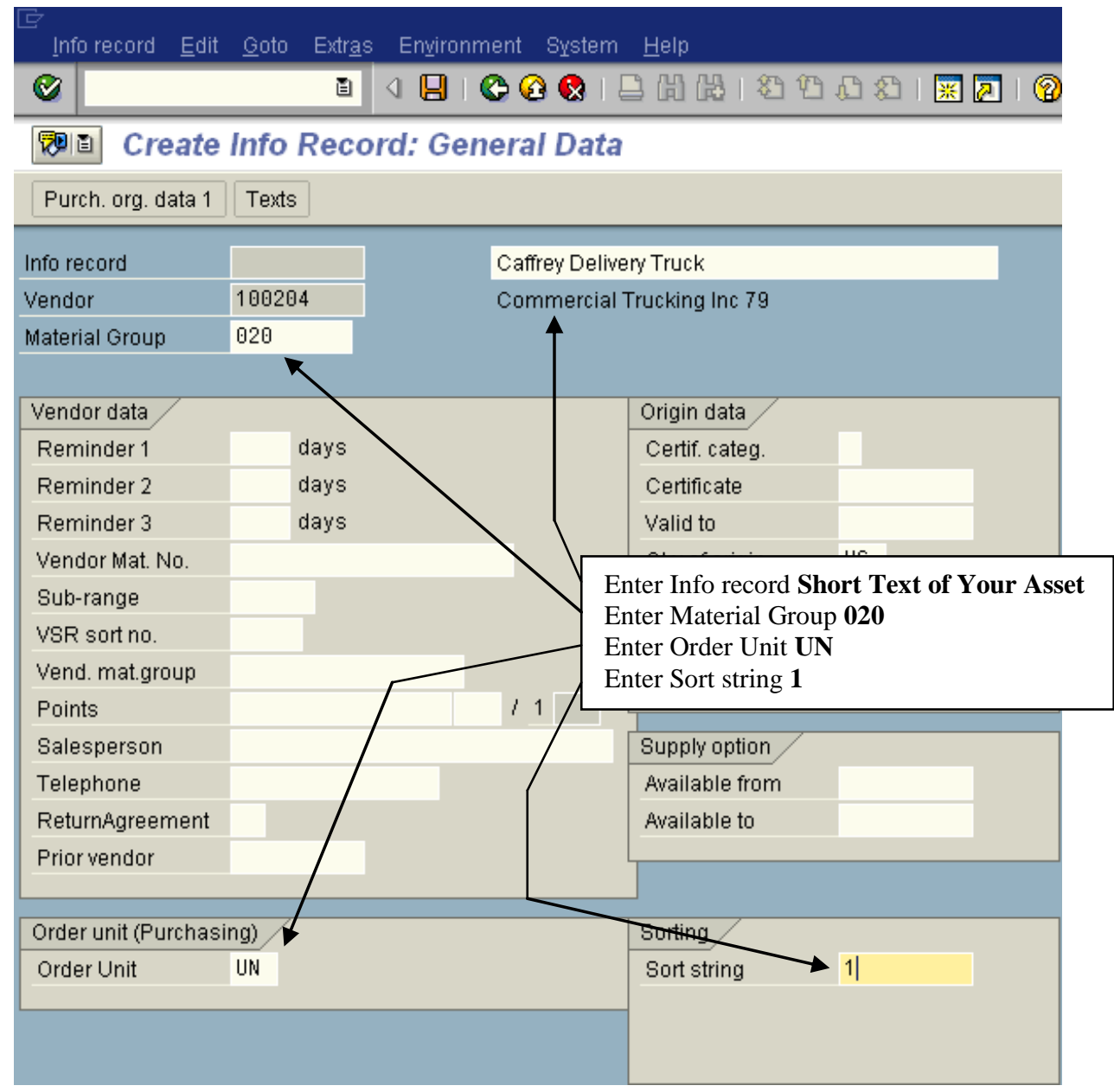

Hit the Purchasing org. data 1 button, then enter the following: 


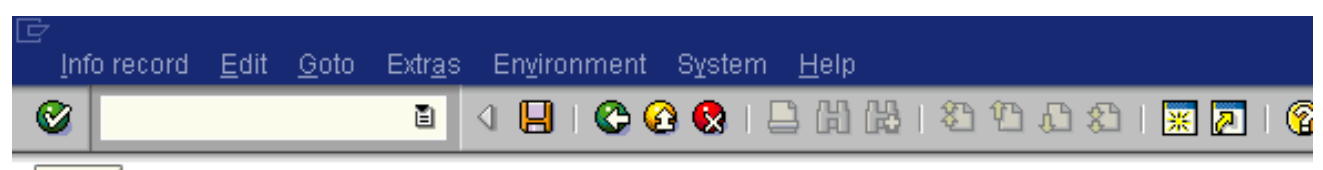

霞目 Change Info Record: Purch. Organization Data 1

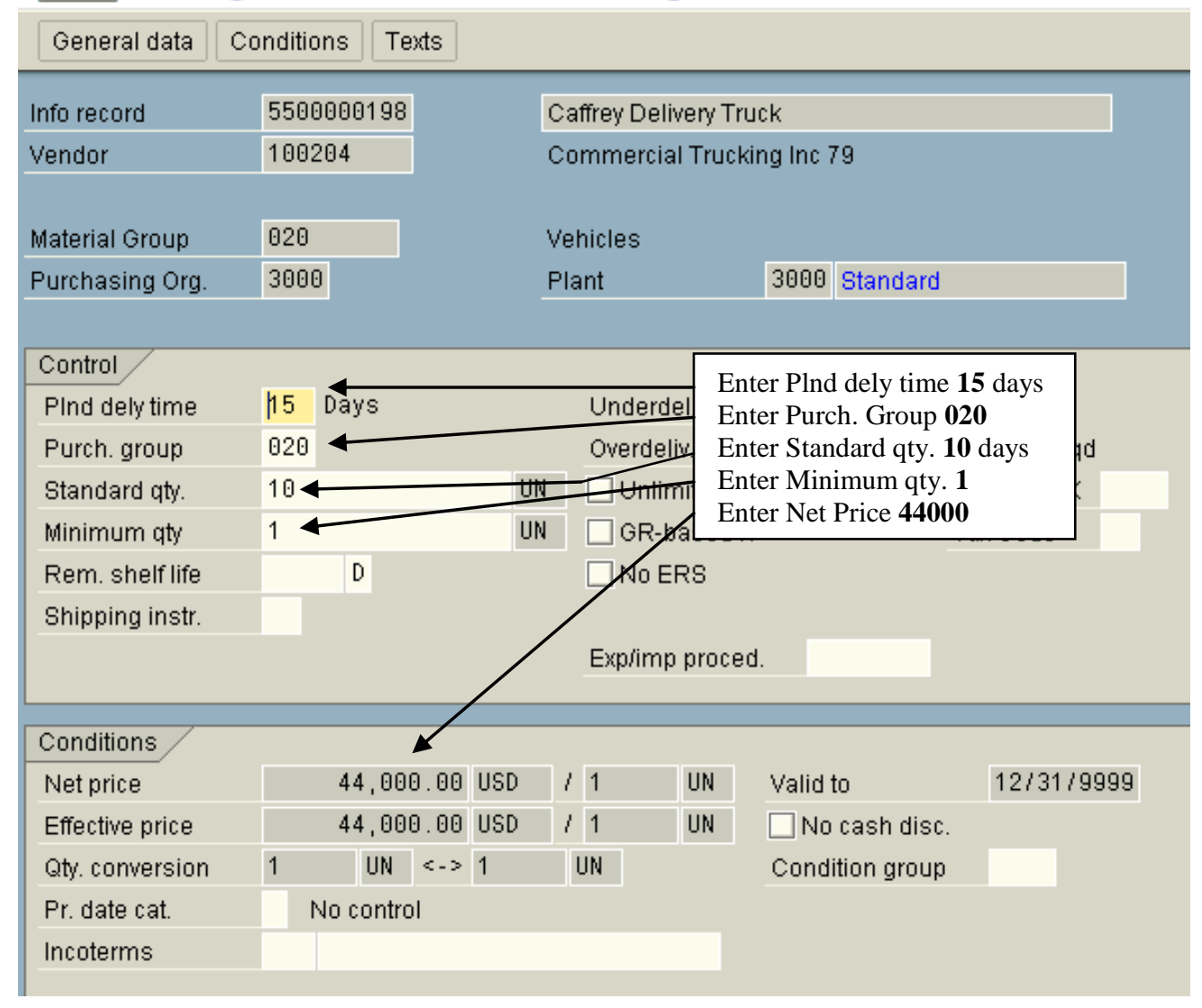

Hit the save ( $(\mathrm{G})$ ) button.

Return to the SAP Easy Access Menu.

\section{Section 2) Asset Acquisition with Materials Management Integration}

It is now time for the actual purchase of the asset. Since the asset and vendor masters have been created it is now possible to go through the purchasing process.

The process will start by creating a purchase order from the vendor that we already created. The next two steps will be to create a goods receipt (to represent that the asset was received) and then to create an invoice verification (to confirm the payment amount to the vendor).

\section{Objectives:}

1. Create Purchase Order

2. Post the Goods Receipt

3. Create the Logistics Invoice Verification 
Objective 1) Create purchase order for the Vendor we created in the first section.

\section{Logistics $\rightarrow$ Materials Management $\rightarrow$ Purchasing $\rightarrow$ Purchase Order $\rightarrow$ Create $\rightarrow$ Vendor/Supplying Plant} Known

On the initial screen, enter the following:

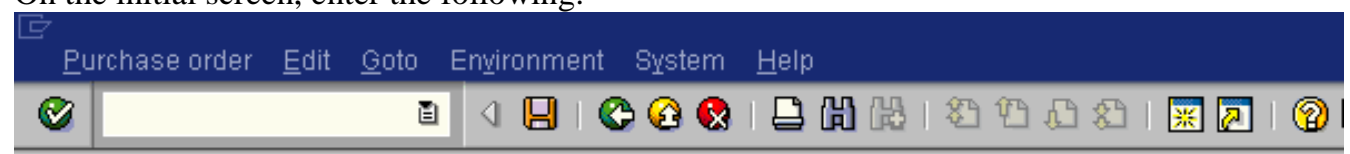

Create Purchase Order

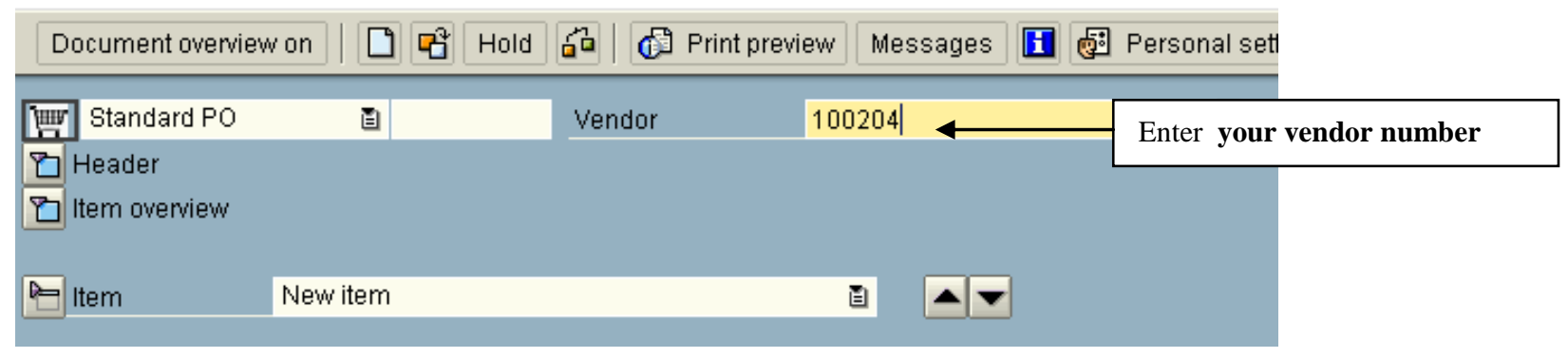

Hit the Enter $(9$ ) button.

On header screen click the Org. Data tab and enter the following:

Note: Purchasing Org. and Company code will be the only fields available. Hit enter, and an error will appear. Then you will be able to enter the purchasing group, as can be seen below:

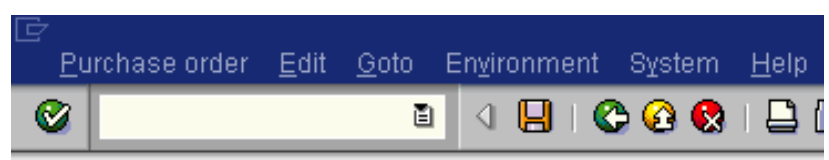

\section{Create Purchase Order}

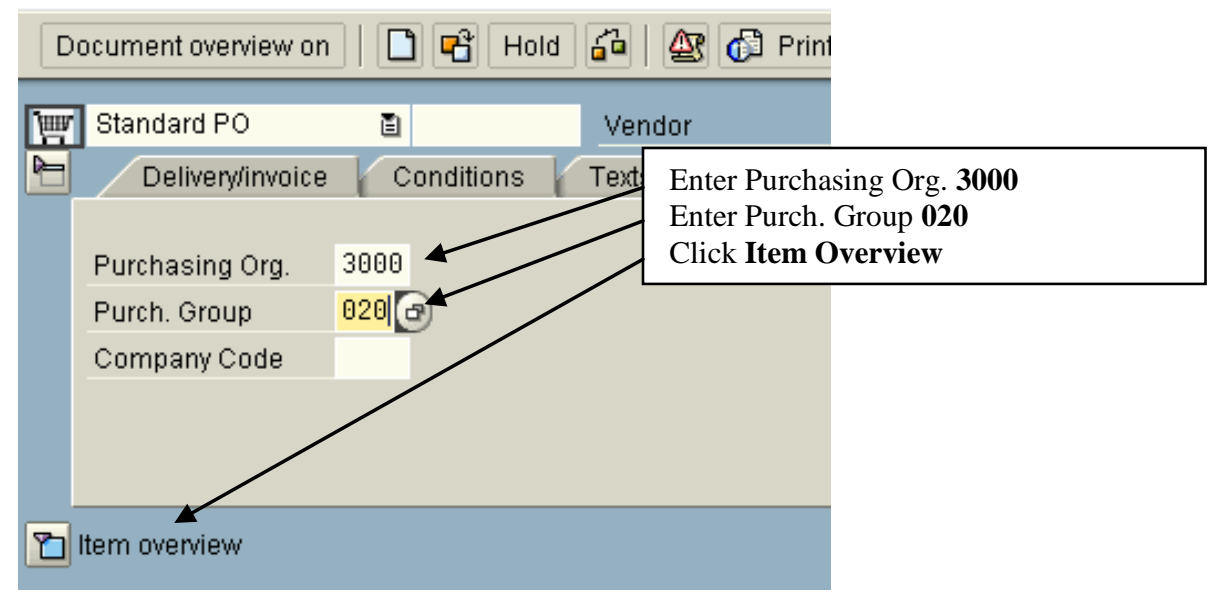

On the Item Overview field (the table with the white boxes) enter the following: 


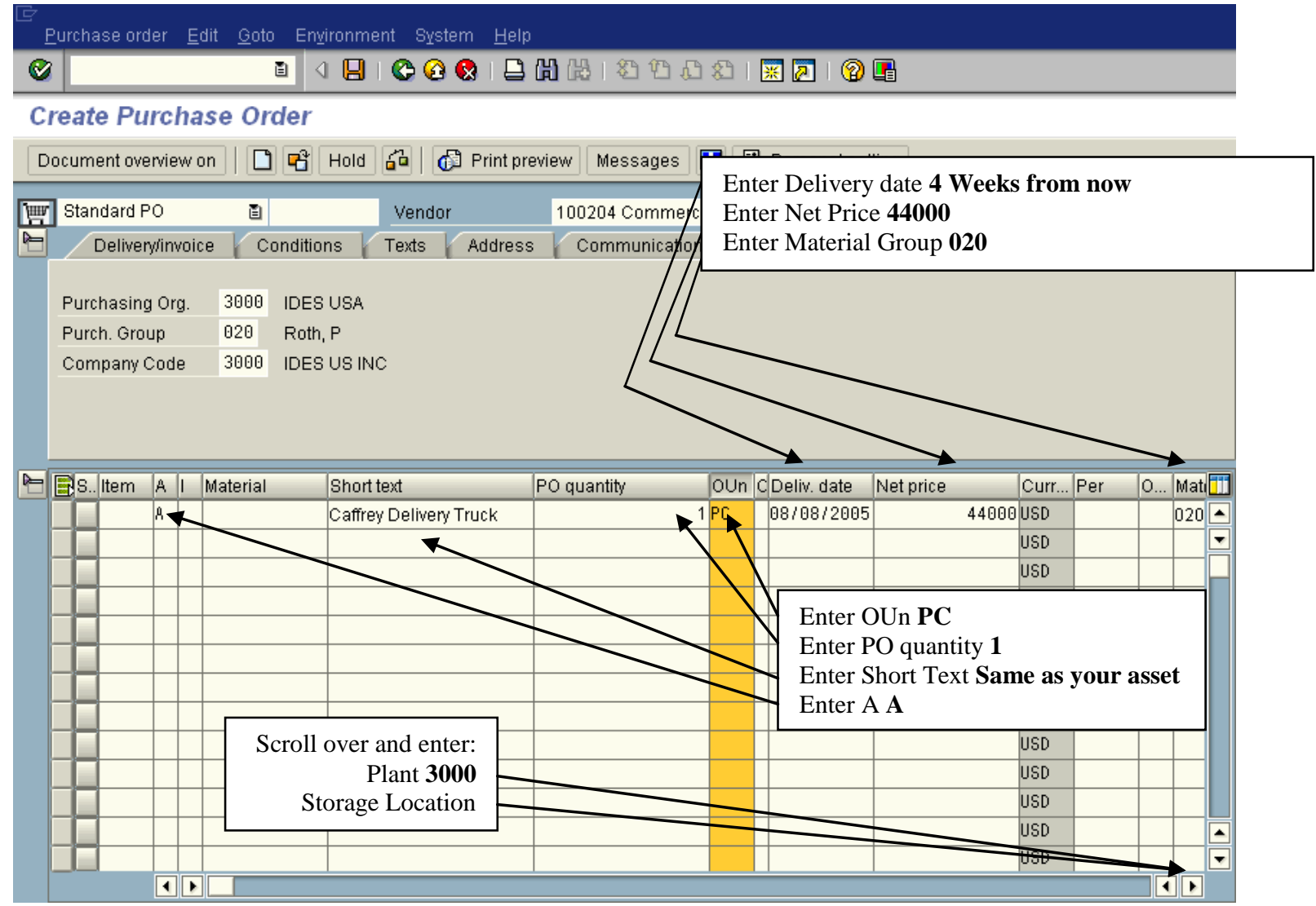

Hit the Enter $($ ) button.

In the Items Detail section enter the following in the Account Assignment tab:

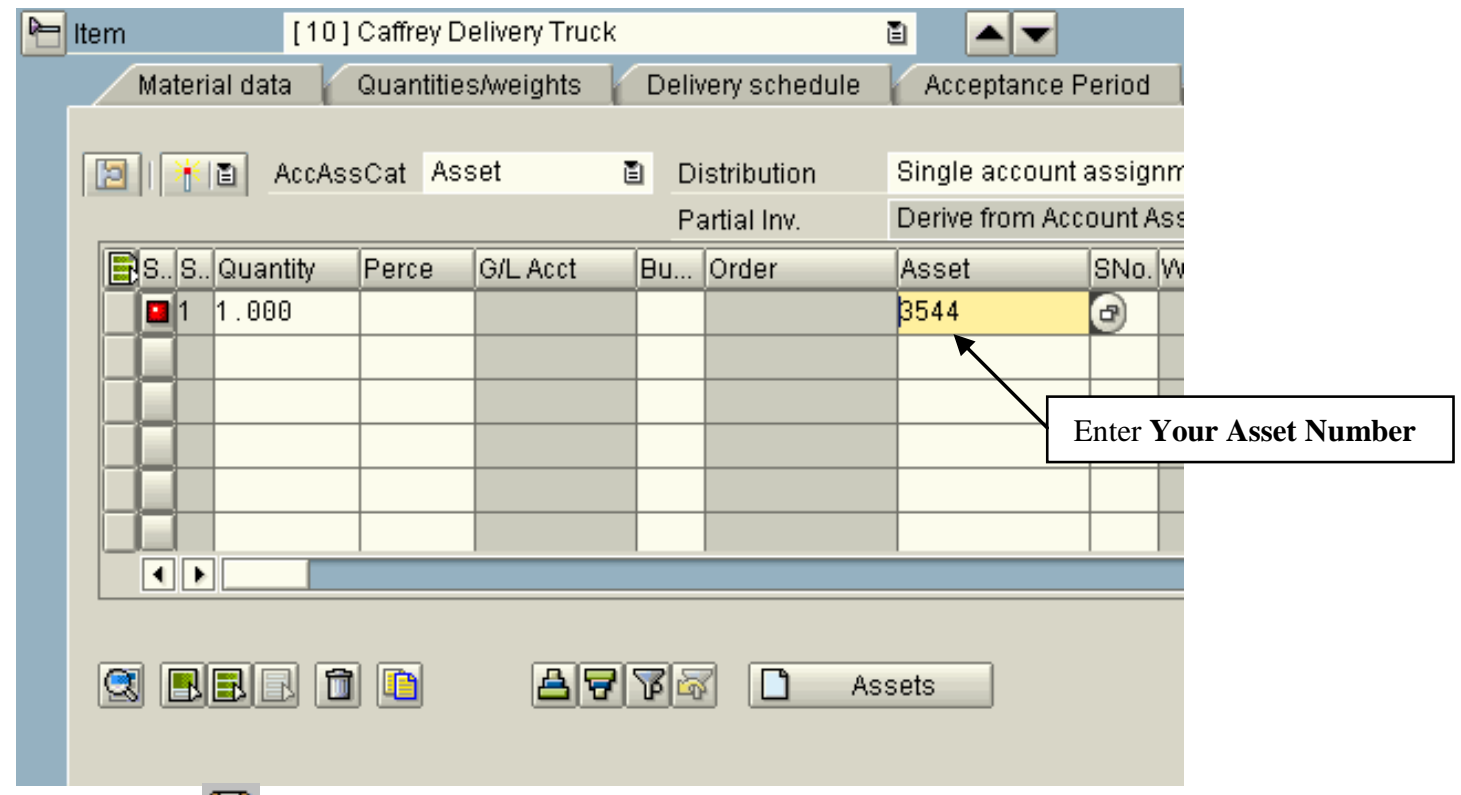

Hit the save (밈) button. 
Write down the number of the Purchase Order (PO) that you just created:

Return to SAP Easy Access Menu.

Objective 2) Create the Goods Receipt Order to post the asset to the books.

Once the delivery truck reaches the warehouse, the goods receipt personnel must confirm the delivery and inspect the truck to make certain its condition is as expected. Go through the steps that the goods receipt clerk would normally go through by following this path on the SAP Easy Access Menu:

\section{Logistics $\rightarrow$ Materials Management $\rightarrow$ Inventory Management $\rightarrow$ Goods Movement $\rightarrow$ Goods Receipt $\rightarrow$ For Purchase Order $\rightarrow$ PO Number Known}

On the initial screen, enter the following:

Goods Receipt Settings System Help
(8)

霜目 Goods Receipt Purchase Order - Patrick Caffrey

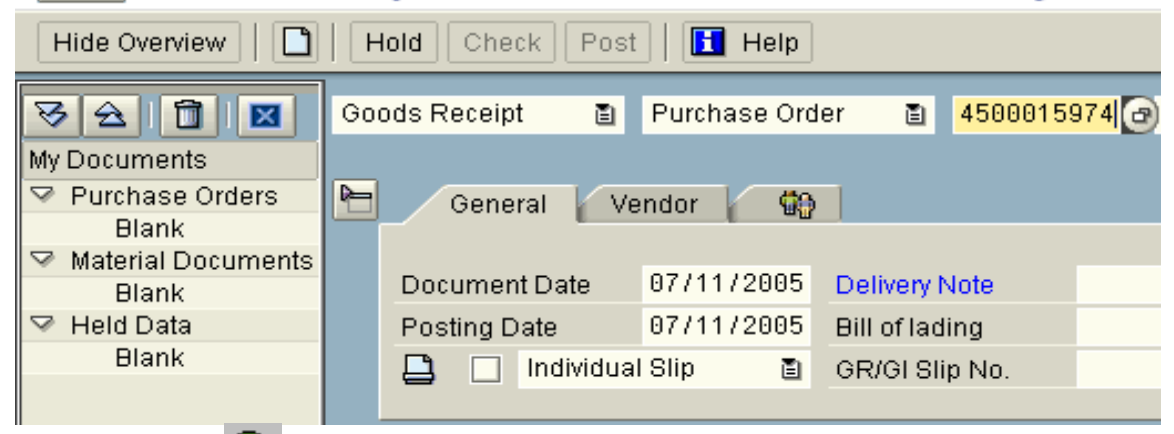

Hit the Enter $(9$ ) button.

At the bottom of the screen check the box that says: Item Ok and also enter the following:

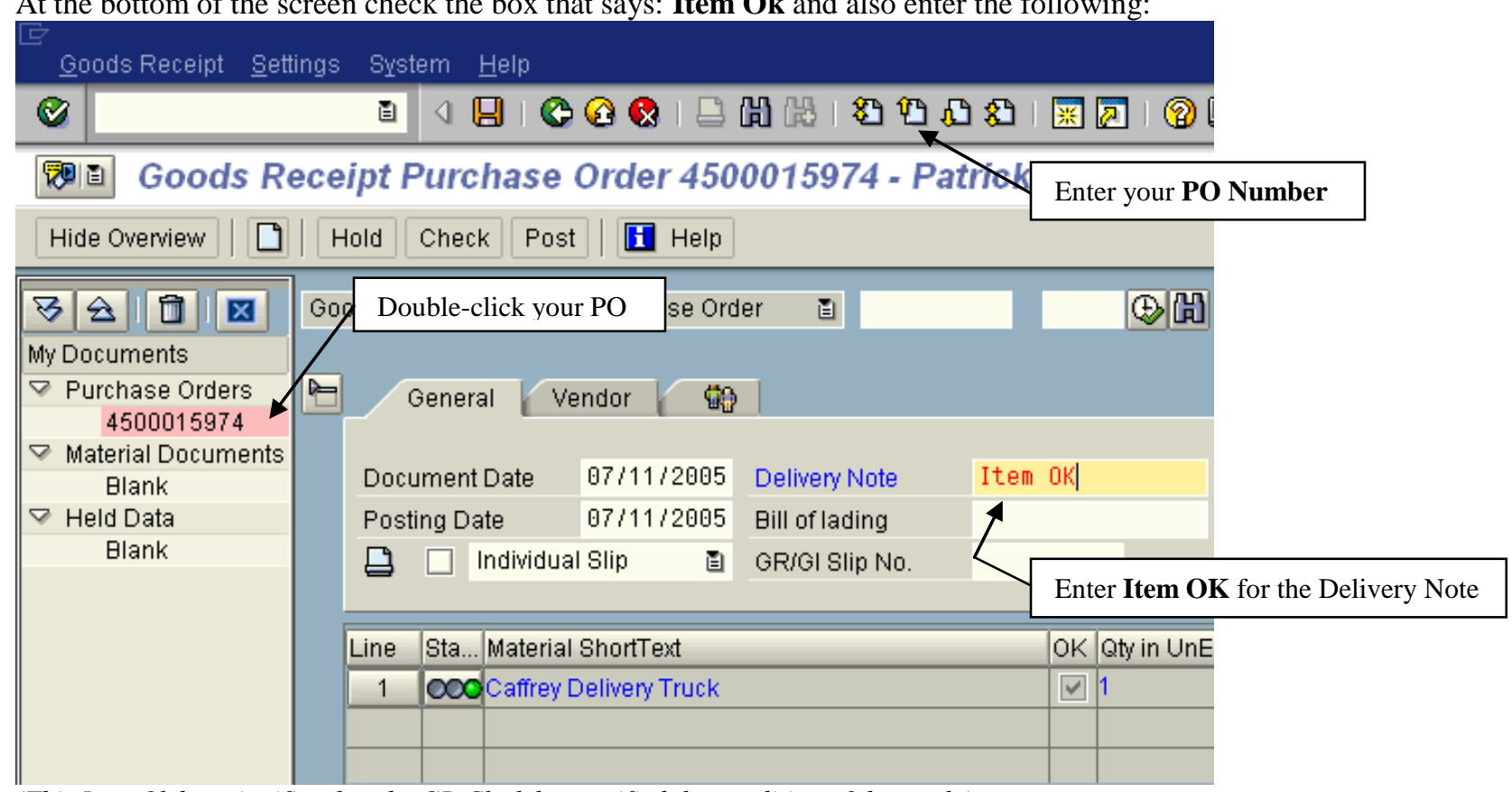

(This Item Ok box signifies that the GR Clerk has verified the condition of the truck.) 
Hit the save ( $(\mathrm{g})$ ) button.

Return to the SAP Easy Access Screen.

Objective 3) Create the Invoice Verification to authorize the amount to be paid to the vendor.

Now that the delivery truck has been received the Invoice Verification must be done to ensure that the proper amount will be paid to the vendor. The person doing this job must be different than the goods receipt clerk in order to segregate duties for internal control purposes.

\section{Logistics $\rightarrow$ Materials Management $\rightarrow$ Logistics Invoice Verification $\rightarrow$ Document Entry $\rightarrow$ Enter Invoice}

On the initial screen, enter the following:

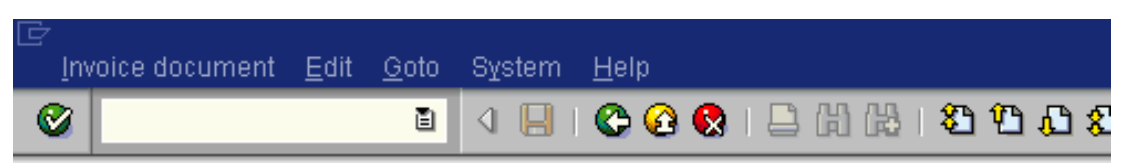

Enter Incoming Invoice: Company Code 3000

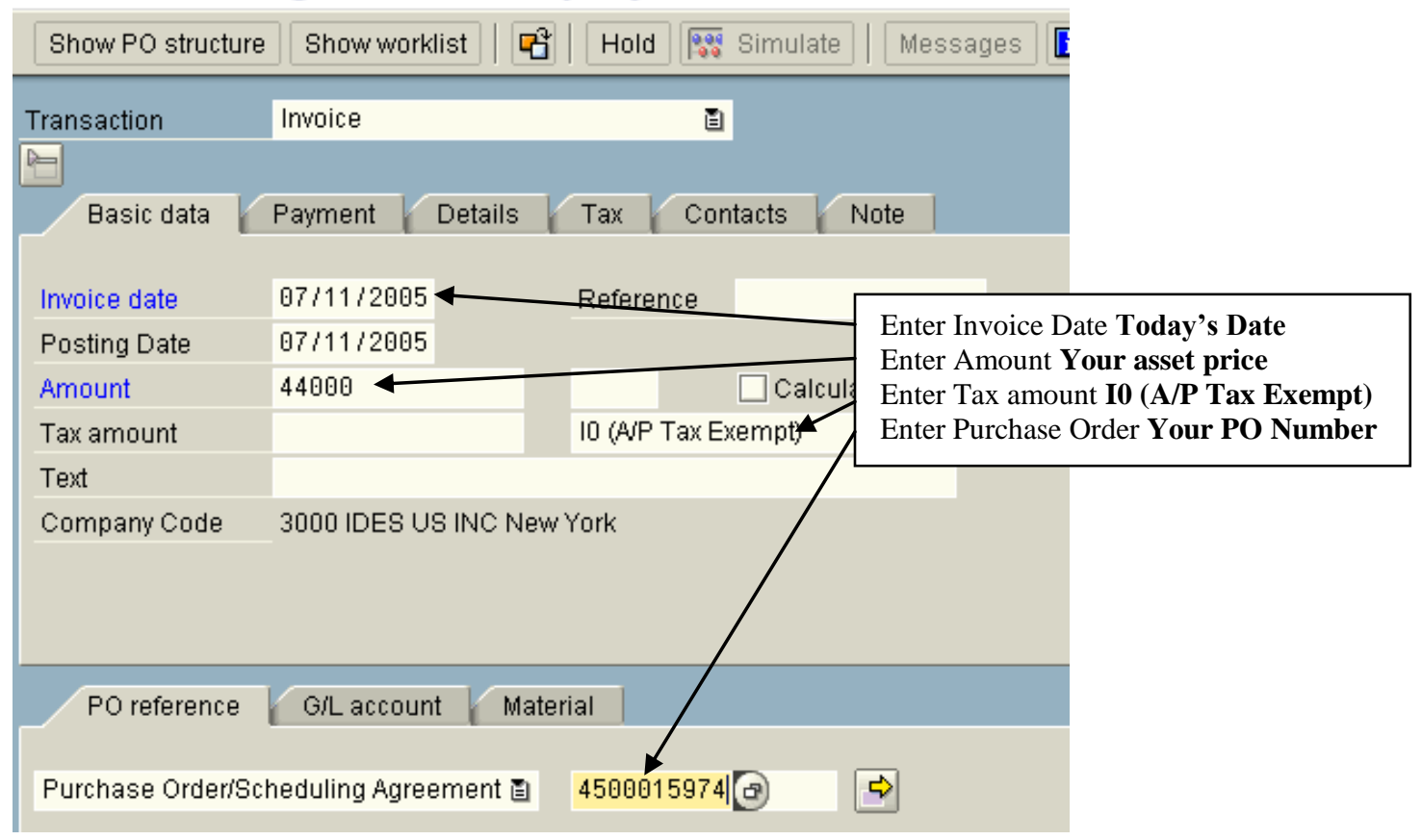

Hit the Enter $(\mathbf{O})$ button.

Now you must re-enter the tax code:

Hit the Save ( $(\mathrm{G})$ button.

\section{Fixed Asset Reporting}

The Asset Explorer can automatically create reports that used to take up a lot of valuable time. In our simulation, we will look at the asset that we created earlier, the Delivery Truck. The first set of steps will include the 
display of planned values, posted values, comparisons of depreciation methods and parameters of the asset. The second set will run through a number of the reports available within the Asset Explorer. The third set will show the different objects related to the asset which are the vendor, cost center, purchase order and the general ledger account.

\section{Objectives:}

1. Display Asset Information

2. Creating and analyzing reports within the Asset Explorer

3. Display the objects related to our asset and their significance

Objective 1) Display a wide variety of information about the asset using the asset explorer.

\section{Accounting $\rightarrow$ Financial Accounting $\rightarrow$ Fixed Assets $\rightarrow$ Asset $\rightarrow$ Asset Explorer}
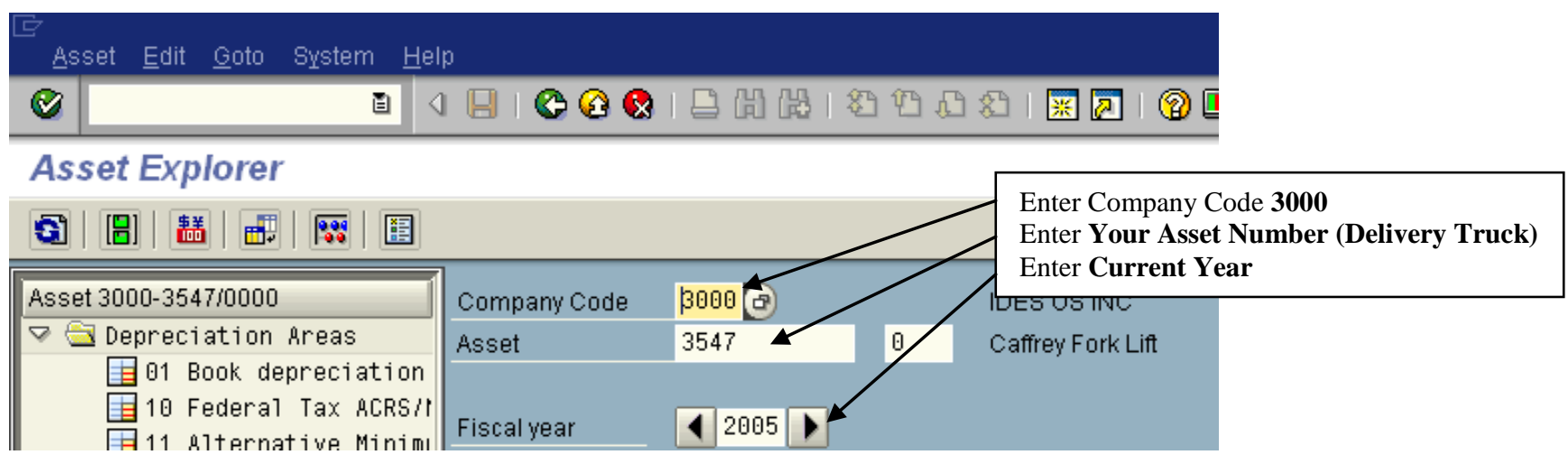

Hit the Enter $(9$ ) button.

In the Transactions box on the bottom of the screen you can see the Goods Receipt and the Credit Memo. Double click the Credit Memo and drill down to the journal entry produced when you acquired the asset.

\begin{tabular}{|c|c|c|c|c|c|c|c|c|c|c|c|}
\hline Itm & PK & Cocd & Account & Account short text & 8mount in LC & Crcy & Amount & Crcy & LC2 amount & LCur2 & Cost Ctr \\
\hline 1 & 31 & 3000 & 100204 & Commercial Trucking & $25,000,00-$ & USD & $25,000,00-$ & USD & & & \\
\hline 2 & 86 & 3000 & 191100 & Goods Rcvd/Invoice R & $27,062.50$ & USD & $27,062.50$ & USD & & & \\
\hline 3 & 75 & 3000 & 21000 & 0000000035470000 & $2,062.50-$ & USD & $2,062.50-$ & USD & & & \\
\hline * & & 3000 & & & & & 0. 00 & USD & & & \\
\hline * * & & & & & & & 0.00 & USD & & & \\
\hline
\end{tabular}

By clicking the (display document header) button you can view who it was that made the entry, when they did it and so forth. Why is this an important feature for management to have?

Click on the Posted Values tab.

Under the Posted dep. Values Book Depreciation section note that there is no depreciation recorded. Why is this?

In the Depreciation Posted/Planned section you can see that the depreciation for the remaining months (per stands for period, displayed by the month).

Click the Comparisons tab.

You will see a schedule of the planned depreciation and the net book value of the asset over its useful life. 
The key aspect of this section is the ability to compare instantly the differences in depreciation expenses and net book values from year to year for different methods of depreciation.

In the upper left hand corner you will see a box with a list of all the different possible methods of depreciation:

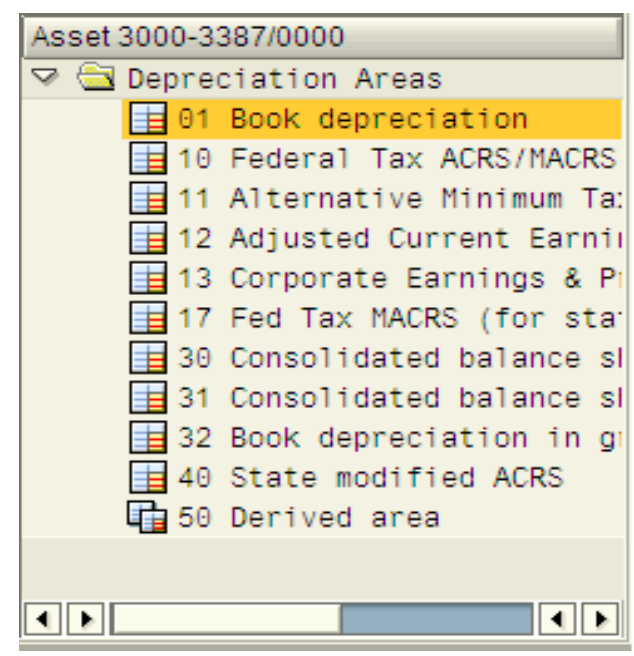

01 Book Depreciation should be listed as the default depreciation method.

Using the schedule on the right side of the screen you can find all the following information (fill this information as it pertains to you asset):

Now click 10 Federal Tax ACRS/MACRS and fill in the following blanks with the new calculated values in the schedule on the right side of the screen:

\begin{tabular}{|l|l|l|}
\hline \multicolumn{1}{|c|}{ Field Name } & \multicolumn{1}{c|}{ Straight-Line } & MACRS \\
\hline Current Year's Net Book Value & & \\
\hline Current Year's Ordinary Depreciation & & \\
\hline Next Year's Net Book Value & & \\
\hline Next Year's Ordinary Depreciation & & \\
\hline
\end{tabular}

Why would management decide to use one method of depreciation versus another?

Click the Parameters tab.

Here one can see all the aspects of the asset. For example; the life of the Delivery Truck, the start date of depreciation, the scrap value and the type of depreciation used. 


\begin{tabular}{|c|c|c|c|c|}
\hline Planned values & Posted values & Comparisons / Parame & eters & \\
\hline Dep. key & \multicolumn{4}{|c|}{ ACE ACE, S/L Half Year - 811 Lives } \\
\hline \multicolumn{5}{|l|}{ Group asset } \\
\hline \multicolumn{2}{|l|}{ Life $/$} & \multicolumn{3}{|l|}{ Start of calculation } \\
\hline Useful life & $005 / 000$ & \multicolumn{2}{|l|}{ Ord.dep.start date } & $07 / 01 / 2005$ \\
\hline Exp. usefl life & $000 / 000$ & \multicolumn{2}{|l|}{ Spec.depreciation } & \\
\hline Remaining life & $005 / 000$ & \multicolumn{2}{|l|}{ Interest calculation } & \\
\hline \multicolumn{2}{|c|}{ Index specifications } & \multicolumn{3}{|c|}{ Further specifications } \\
\hline \multicolumn{2}{|l|}{ Index series } & \multicolumn{3}{|c|}{ Changeoveryear 0000} \\
\hline \multirow[t]{4}{*}{ Aging index } & & Invest.support & \\
\hline & & Scrap value & \multicolumn{2}{|l|}{0.90} \\
\hline & & \multirow{2}{*}{ Scrap Value * } & \multicolumn{2}{|c|}{ 0. 000000000000} \\
\hline & & \\
\hline \multicolumn{2}{|c|}{ Display dep. key } & & & \\
\hline
\end{tabular}

Objective 2) Creating and analyzing reports within the Asset Explorer

\section{Accounting $\rightarrow$ Financial Accounting $\rightarrow$ Fixed Assets $\rightarrow$ Asset $\rightarrow$ Asset Explorer}

Hit the 田 (call asset reports) button and the Select Report box will appear.

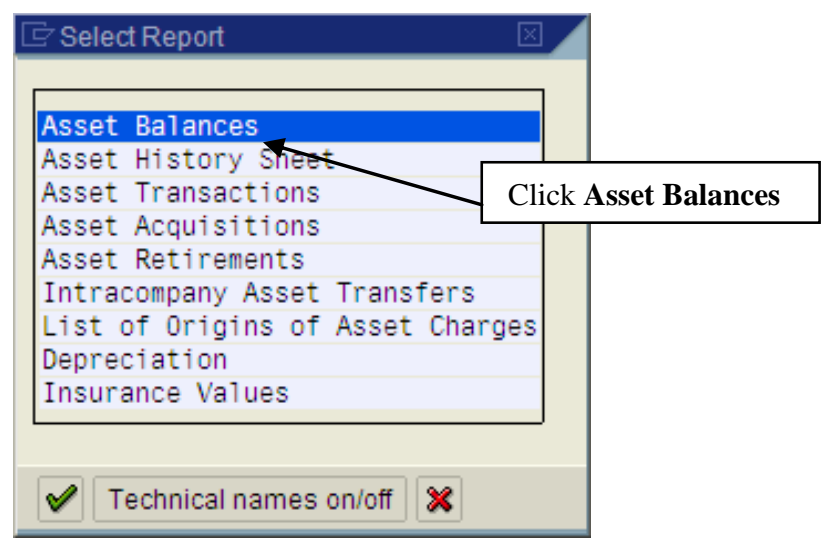

Hit the Enter $(9$ ) button.

According to this report what is the current book value of your asset? 


\section{E Select Report}

Asset Balances

Asset History Sheet

Bsset Transactions

Asset Acquisitions

Asset Retirements

Intracompany isset Transfers

List of Origins of isset Charges

Depreciation

Insurance values

Technical names onioff \&

Hit the Enter $($ ) button.

This report will show you all the transactions your asset has been involved in including the acquisition and the goods receipt. You can drill down on each transaction to see the journal entries.

Return to main Asset Explorer Screen

\section{NOTES}

